\title{
Femoroasetabular sıkışmada direkt radyoloji
}

\author{
Plain radiography in femoroacetabular impingement
}

\author{
Mehmet Aşık, Gökhan Polat
}

İstanbul Üniversitesi İstanbul Tıp Fakültesi, Ortopedi ve Travmatoloji Anabilim Dalı

\begin{abstract}
Femoroasetabular sıkışma, günümüzde farkındalığı giderek artan preartrozik bir patolojidir. Radyolojik inceleme, femoroasetabular sıkışma tanı aşamasının temelini oluşturmaktadır ve düz grafi femoroasetabular sıkışma tanısında kullanılan en önemli görüntüleme yöntemidir. Erişkin hastalarda kalça ağrısının tam olarak değerlendirilmesi için, hastalar pelvis anteroposterior (AP) grafi, pelvis frog-leg grafisi, cross-table lateral grafi, Dunn grafisi $\left(90^{\circ}\right)$, modifiye Dunn grafisi $\left(45^{\circ}\right)$ ve false-profile grafileriyle değerlendirilmelidir. Bu yapılan tetkiklerde femoroasetabular sıkışma tanısının doğru konulabilmesi için, radyografik incelemeler ideal görüntüleme standartlarında çekilmelidir. Standart grafiler üzerinde yapılacak olan; CE açısı, Tönnis açısı, alfa açısı, femoral baş-boyun ofseti ve femoral baş-boyun ofset oranı ölçümleri, femoroasetabular sıkışma tanısı konulmasında yardımcı olacaktır.
\end{abstract}

Anahtar sözcükler: radyoloji, konvansiyonel; alfa açısı; Tönnis açısı; merkez-kenar açısı
Femoroacetabular impingement is a prearthrosic disease and its awareness has been increasing nowadays. Radiological analysis is the main diagnostic tool in the diagnosis of femoroasetabular impingement and plain radiographs are the most important radiological method in this evaluation. For a complete assessment of hip pain in adult patients; pelvis anteroposterior (AP) radiography, pelvis frog-leg radiography, cross-table lateral radiography, Dunn radiography, modified Dunn radiography and false-profile graphy should be obtained. For the accurate diagnosis of femoroacetabular impingement, these plain radiographies should be displayed in ideal standard positions and methods. Femoroasetabular impingement can be diagnosed with the help of the CE angle, Tönnis angle, alpha angle, femoral head-neck offset and femoral head-neck offset ratio measurements on these standard radiographies.

Key words: radiology, conventional; alpha angle; Tönnis angle; center-edge angle emoroasetabular sıkışma (FAS), Ganz ve arkadaşları tarafından 2003 yılında tanımlanması sonrasında, günümüzde farkındalığı giderek artan preartrozik bir patoloji olarak kabul görmektedir. ${ }^{[1-3]}$ Radyolojik inceleme, FAS tanı aşamasının temelini oluşturmaktadır ve konvansiyonel radyografi, FAS tanısında kullanılan en önemli görüntüleme yöntemidir. ${ }^{[4,5]}$

Kalça ağrısı nedeniyle polikliniğe başvuran gençerişkin hastalarda, gelişimsel kalça diplazisi, FAS gibi morfolojik bozukluklar ön planda düşünülmeli ve yapısal bozuklukların varlığı düz grafilerle tetkik edilmelidir. ${ }^{[6]}$ Erişkin hastalarda kalça ağrısının bu açıdan tam olarak değerlendirilmesi için; pelvis anteroposterior (AP) grafi, pelvis frog-leg grafisi, cross-table lateral grafi, Dunn grafisi, modifiye Dunn grafisi ve false-profile grafiler çekilmelidir. Bu yapılan tetkiklerde FAS tanısının doğru konulabilmesi için, radyografik incelemeler ideal görüntüleme standartlarında çekilmelidir.

\section{PELVIS AP}

Pelvisin anteroposterior grafisi supin pozisyonda ve femur boynunun daha iyi görülmesi için, alt ekstremiteler $15^{\circ}$ iç rotasyonda çekilmelidir. 1,2 metre mesafeden gelen ışın, simfizis pubisin üst kısmına santralize edilmelidir (Şekil 1).

Pelvis AP grafisi, asetabulum ve femur morfolojisini oldukça iyi gösterir. Çekilen grafiler, pelvik tilt ve rotasyon açısından değerlendirilmelidir. Pelvis AP grafisinde, koksiks simfizis pubis ile aynı hatta olmalı ve bire bir grafide aralarında yaklaşık $3 \mathrm{~cm}$ olmalıdır.

- Illetişim adresi: Prof. Dr. Mehmet Aşık, İstanbul Üniversitesi İstanbul Tıp Fakültesi Ortopedi ve Travmatoloji Anabilim Dalı, Çapa, Fatih, İstanbul Tel: 0532 - 2415693 e-posta: mehmetasik@hotmail.com

- Geliș tarihi: 10 Ocak 2016 Kabul tarihi: 10 Ocak 2016 

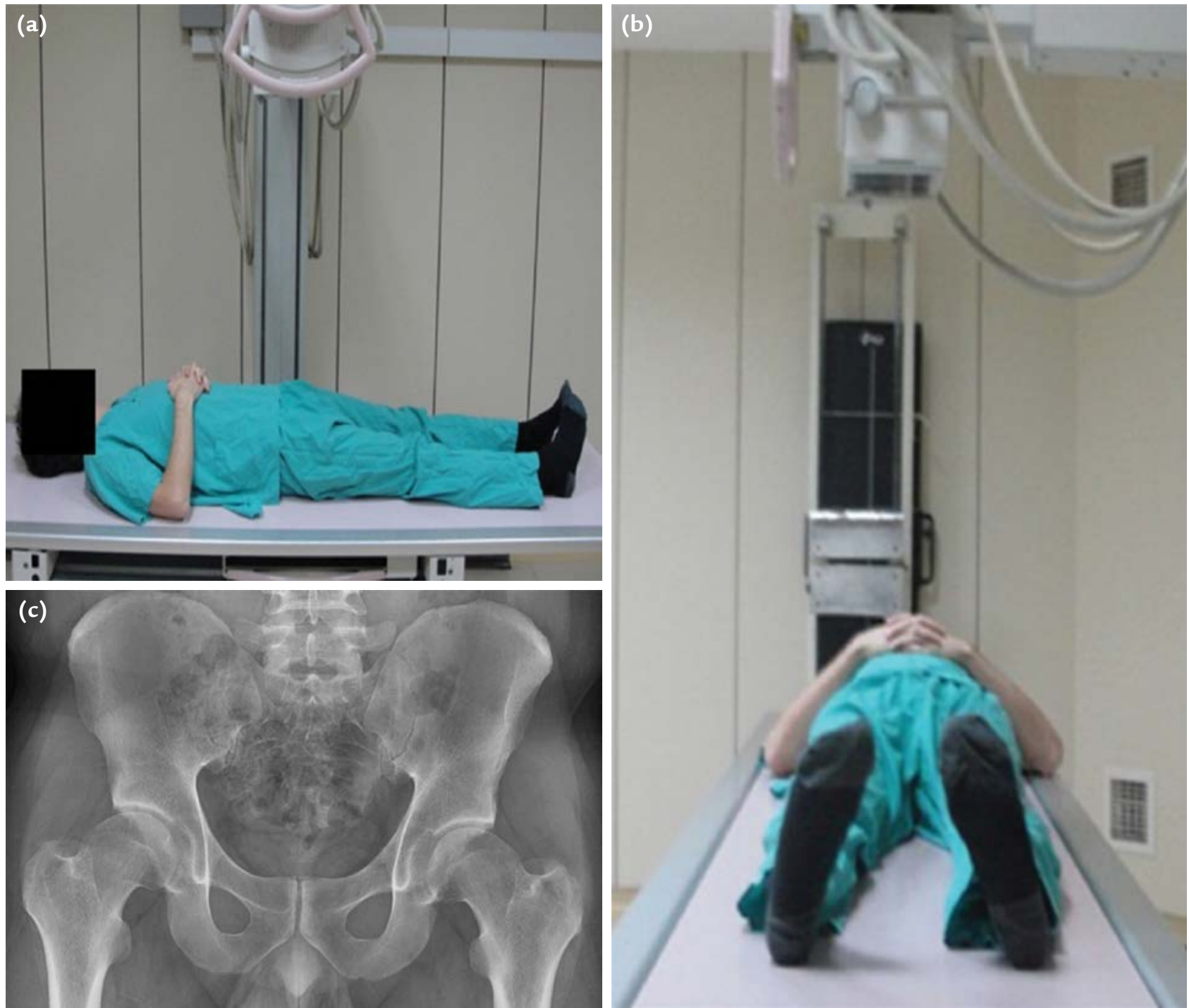

Şekil 1. a-c. Pelvis AP grafisinde hastanın pozisyonlanması (a, b). Yirmi iki yaşındaki erkek hastanın pelvis AP grafisinde silah kabzası (pistol grip) deformitesi görülmekte (c).

Rotasyon açısından ise, obturator foramenler, iliak kanatlar ve gözyaşı figürleri simetrik olmalıdır.

\section{CROSS-TABLE LATERAL GRAFi}

Cross-table lateral grafi için, hasta supin pozisyondayken karşı kalçası $80^{\circ}$ fleksiyona alınarak röntgen masasına yatırılır. İncelenen kalça $15^{\circ}$ iç rotasyondayken, X-ışını tüpü karşı ekstremitenin ayak kısmına alınır ve ışın masaya paralel olarak, ekstremiteye $45^{\circ}$ açıda femur proksimali mediyaline santralize edilir. Özellikle proksimal femurun görüntülemesinde değerli olan bu grafi, cam lezyonu tanısında değerli bir grafidir (Şekil 2).

\section{FROG-LEG GRAFi}

Frog-leg grafi, hasta supin pozisyonda kalça $45^{\circ}$ abduksiyonda, diz $30-40^{\circ}$ fleksiyonda, topuk ise karşı tarafın diz mediyaline dayalı ya da bilateral çekiliyorsa, karşı topuğa dayalı pozisyonda çekilir. Proksimal femurun görüntülenmesinde, özellikle femur boynu anteriorundaki cam lezyonlarının tanısında değerlidir. Bununla birlikte, femoral anteversiyon konusunda da bilgi verir (Şekil 3).

\section{DUNN GRAFISI}

Dunn grafisi, hasta supin pozisyonda kalça $90^{\circ}$ fleksiyonda, nötral rotasyonda ve $20^{\circ}$ abduksiyonda çekilir. 

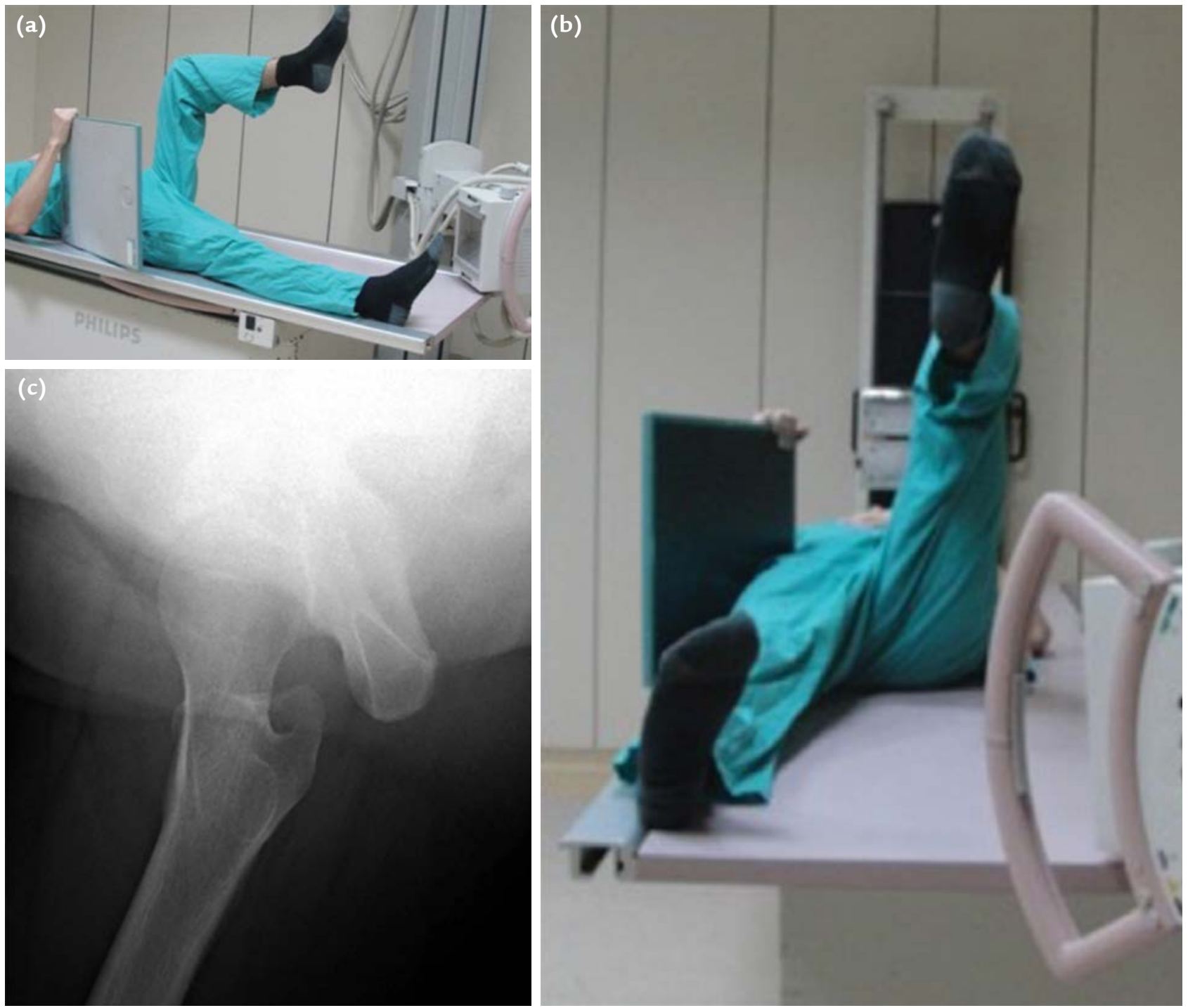

Şekil 2. a-c. Cross-table lateral grafide hastanın posizyonlanması.

\section{MODIFIYE DUNN GRAFisi}

Modifiye Dunn grafisi ( $45^{\circ}$ Dunn grafisi), hasta supin pozisyonda, kalça $45^{\circ}$ fleksiyonda, nötral rotasyonda ve $20^{\circ}$ abduksiyonda çekilir. Cam deformitesinin en sık görüldüğü femur baş-boyun bileşkesi anterolateralini en iyi gösteren grafidir. Bu açıdan, alfa açısı ölçümü için de ideal bir grafidir. Tek kalça için görüntüleme yapılabileceği gibi, bilateral görüntüleme de yapılabilir (Şekil 4).

\section{FALSE-PROFILE GRAFi}

False-profile grafi, asetabular örtünme yetersizliği olan hastalarda değerlidir. Hasta ayakta, pelvis kasete göre yaklaşık $65^{\circ}$ kadar rotasyonda, ayak kasete paralel pozisyonda çekilir. İleri evre FAS hastalarında, eklem posteroinferiorundaki artrozik değişiklikleri göstermesi açısından da değerlidir.

\section{RADYOLOJIK ÖLÇÜMLER VE AÇISAL DEĞERLENDIRMELER}

Konvansiyonel radyografilerde elde edilen görüntülerin değerlendirmesi, FAS tanısının konmasında objektif bir değerlendirme yapılması ve mevcut morfolojik bozuklukların rakamsal olarak ifade edilmesi amacıyla, birçok açısal parametre literatüre kazandırılmıştır. ${ }^{[4]}$ 

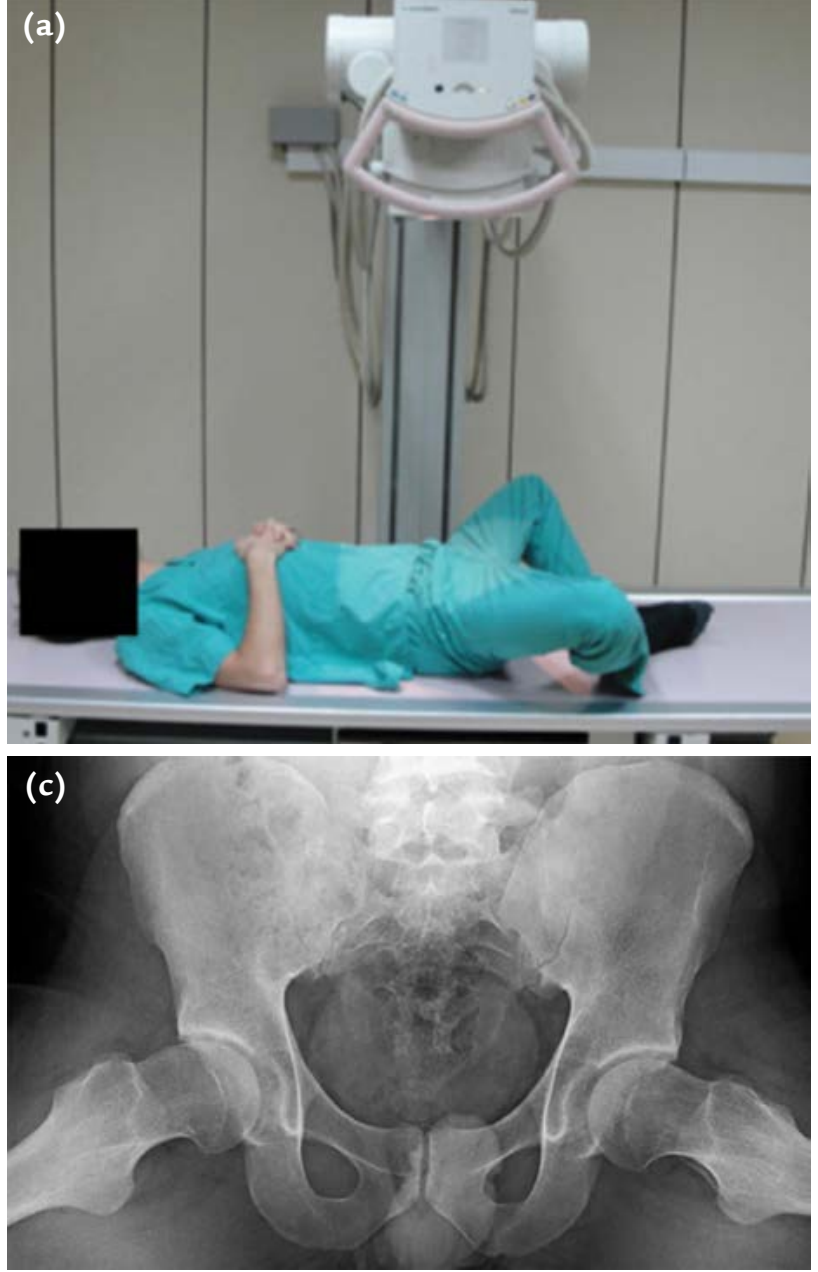

Şekil 3. a-c. Frog-leg grafisinde hastanın pozisyonlanması (a, b). Bilateral cam deformitesi olan hastanın frog-leg grafisi

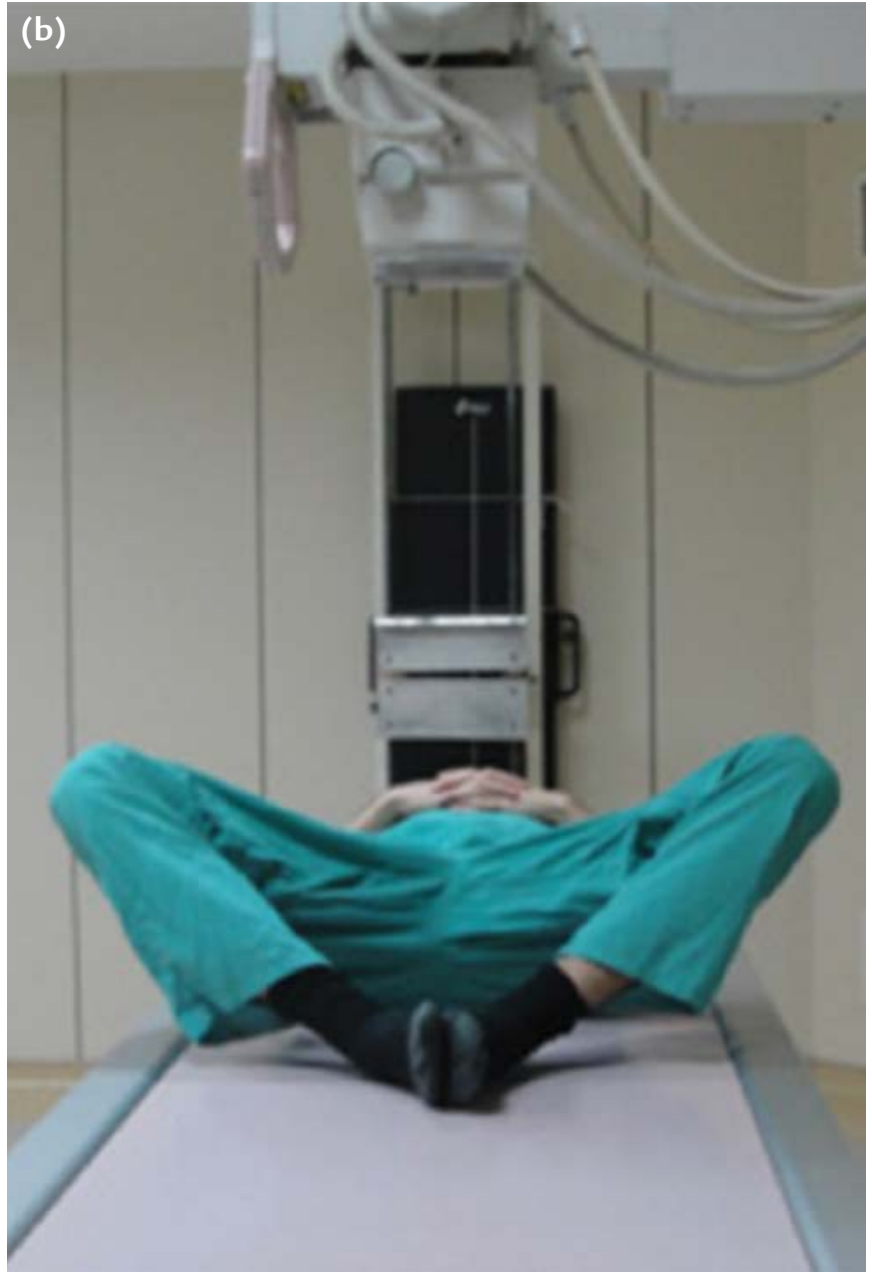
görülmekte (c).

\section{Asetabular Taraf Değerlendirmesi}

Pelvis AP grafisi, genel olarak asetabular taraf problemlerin değerlendirilmesinde oldukça yararlıdır. ideal olarak çekilmiş olan bir Pelvis AP grafisi; asetabulum derinliği, inklinasyonu, versiyonu, örtünme yetersizliği ya da aşırı örtünme konusunda bize bilgi verebilir.

FAS açısından, asetabular tarafta global bir aşırı örtünme, fokal anterior aşırı örtünme ya da asetabular retroversiyon görülebilir. ${ }^{[2,7,8]}$ Global aşırı örtünme, koksa profunda ya da asetabular protrüzyon gibi, asetabular fossa veya femur başının ilioiskial çizgiye temas ettiği ya da bu çizgiyi geçtiği radyolojik görünümdür. Global bir pincer tipi sıkışmaya yol açar. Fokal anterior aşırı örtünme, pincer tipi sıkışmaya yol açan diğer bir asetabular morfolojik bozukluktur. Bir diğer pincer tipi sıkışmaya yol açan asetabular morfolojik bozukluk, asetabular retroversiyondur. Bu durumda, Pelvis AP grafisinde çaprazlama bulgusu ( 8 bulgusu, cross-over sign) olarak adlandırılan bir görüntü görülebilir (Şekil 5). Buna rağmen, bu bulgunun asetabular versiyon kusuru olmaksızın görülebildiğini bildiren çalışmalar da literatürde mevcuttur. ${ }^{[9,10]} \mathrm{Bu}$ nedenle, asetabular versiyonun bilgisayarlı tomografi ile değerlendirilmesi, tanı aşamasında daha doğru olacaktır. [11]

Asetabular inklinasyon içinse, Tönnis açısı ve lateral merkez-kenar açısı (Wiberg merkez-kenar açısı) değerlendirilmelidir. Tönnis açısı için, gözyaşı figürlerini birleştiren bir çizgi çizilir. Bu çizgiye paralel olarak, sourcil'in inferior ucundan geçen ikinci bir çizgi çizilir. Sourcil'in inferiorundaki nokta ile en lateralindeki noktayı birleştiren bir çizgi daha çizilir. Kesişmelerinden elde edilen açı Tönnis açısıdır ve normalde $0-10^{\circ}$ arasında olmalıdır. Bundan büyük değerler örtünme 

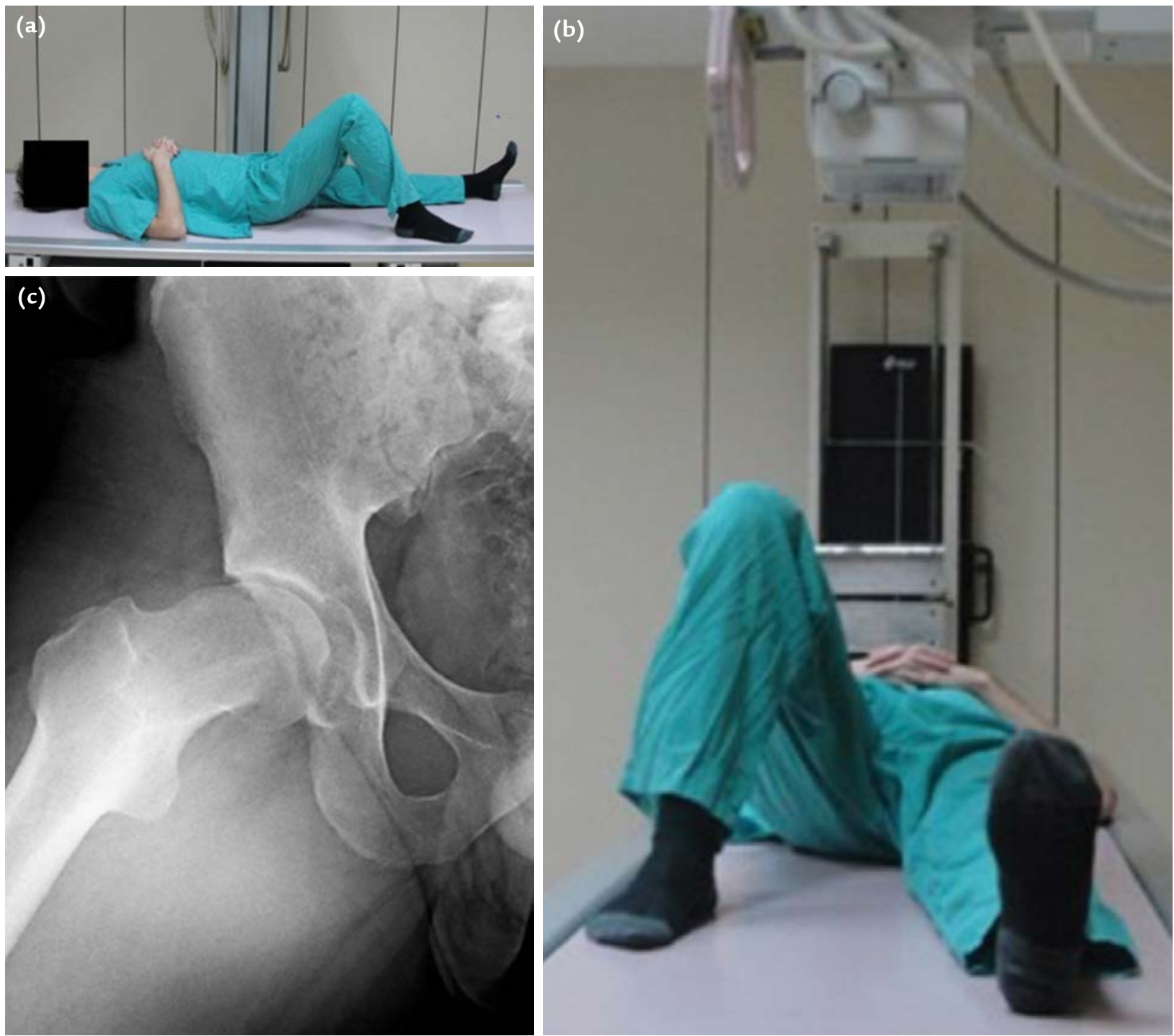

Şekil 4. a-c. Modifiye Dunn grafisinde hastanın pozisyonlanması (a, b). Sağ kalça için yapılan görüntülemede cam deformitesi görülmekte (c).

yetersizliğinin, küçük (negatif) değerler ise pincer tipi sıkışmanın bulgusudur. Lateral merkez-kanar açısı ise, femur başı orta noktasından çıkılan pelvise dik çizgi ile sourcil'in superolateraline çizilen çizgiler arasındaki açıdır. Bu açının $25^{\circ}$ 'nin altında olması, örtünme yetersizliğin göstergesidir. Açının $39^{\circ}$ 'nin üzerinde olması ise, asetabulumun aşırı örtünmesinin bir göstergesidir. Asetabular örtünmenin değerlendirilmesi için kullanılan diğer bir yöntem de, femur başı örtünme indeksidir. Horizontal düzlemde, femur başının örtünmeyen kısmının femur başına oranı ile elde edilir. Bu oranın \%25'in üzerinde olması, displazi olarak tanımlanır (Şekil 6). ${ }^{[7]}$

\section{Femoral Taraf Değerlendirmesi}

Femoral tarafin morfolojik değerlendirmesinde, proksimal femurun lateral grafileri olan frog-leg, crosstable lateral grafi, Dunn ve Modifiye Dunn grafileri dışında Pelvis AP grafisi de kulanılabilir.

Femur proksimalinin morfolojik değerlendirmesinde; femur başı sferisitesi, kalça rotasyon merkezinin yeri, femur baş-boyun ofseti ve eklem uyumu değerlendirilmelidir. FAS tanısı açısından, femur proksimalindeki morfolojik bozuklukların tanımlanabilmesi ve tanısal sınır değerler ortaya konması için bazı açısal parametreler belirlenmiştir (Şekil 7). ${ }^{[7,8,12,13]}$ 

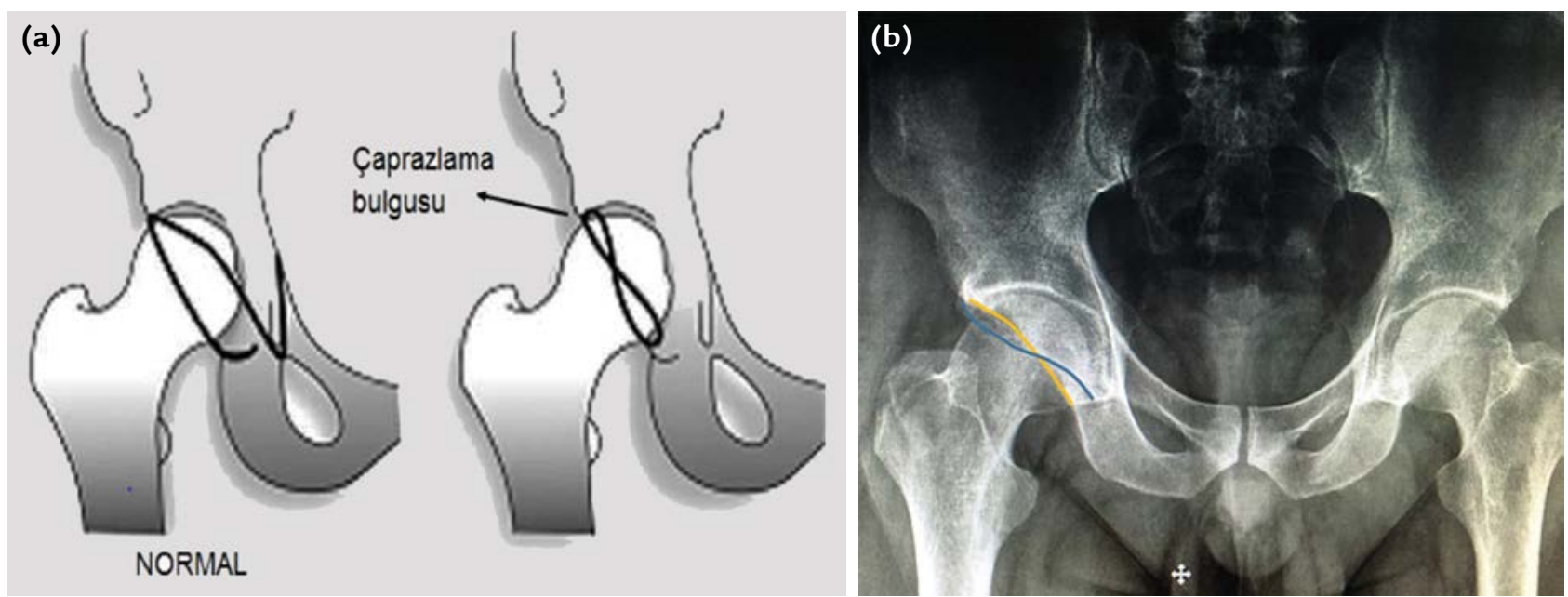

Şekil 5. a, b. AP grafide asetabular versiyon değerlendirmesi ve patolojik çaprazlama bulgusu (a). Kombine sıkışma bulguları olan 40 yaşındaki hastanın sağ kalçasında çaprazlama bulgusu görülmekte (b).
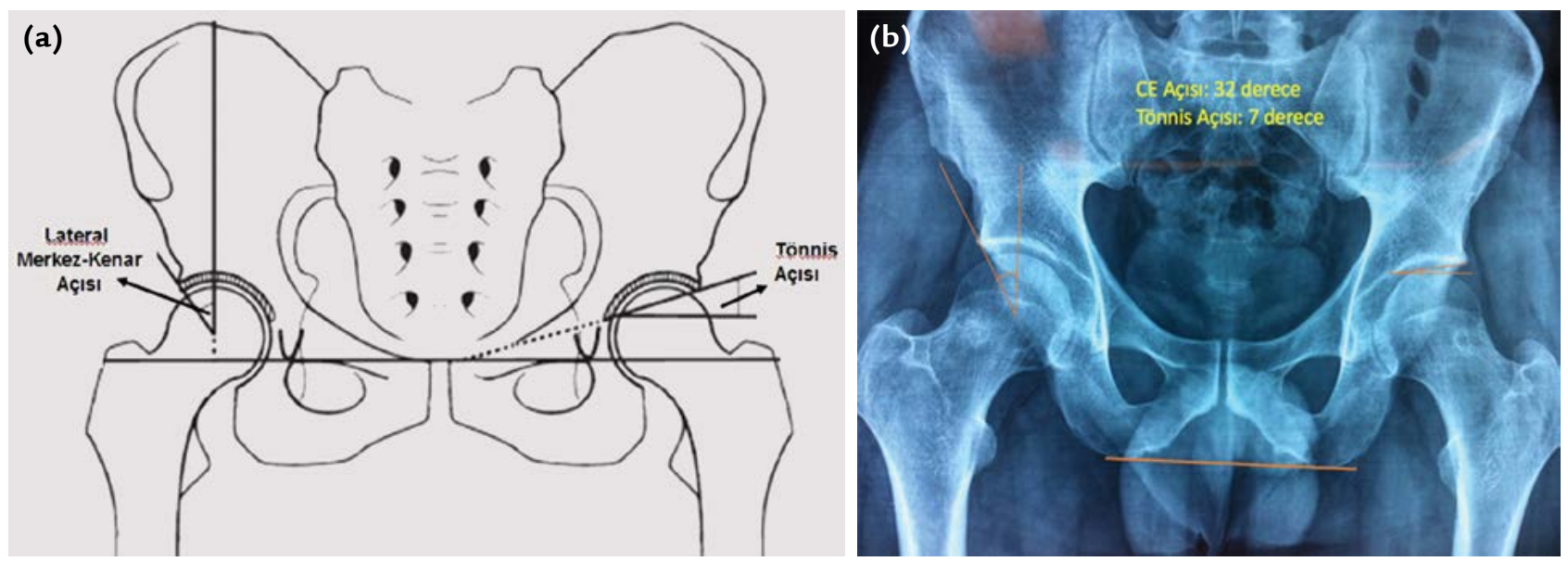

Şekil 6. a, b. Lateral merkez-kenar açısı ve Tönnis açısının ölçümünün gösterildiği çizimler.

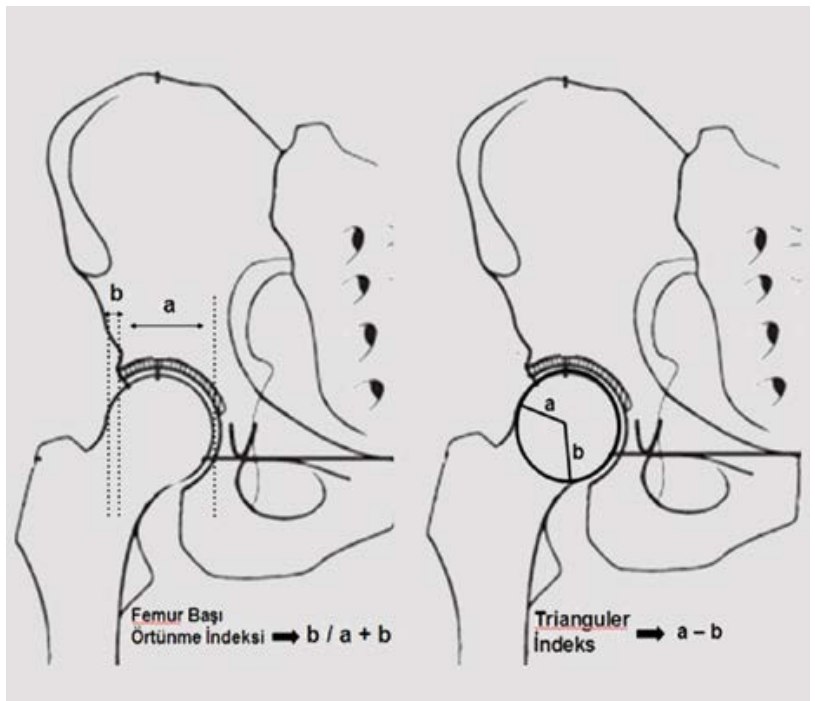

Şekil 7. Femur başı örtünme indeksi ve triangüler indeksin ölçümünün gösterildiği çizimler.
Alfa açısı, esas olarak MR aksiyel görüntüleri üzerinde tanımlanmış bir ölçüm olmasına rağmen, AP, crosstable lateral, frog-leg ve Modifiye Dunn grafileri üzerinde de ölçülebilir. ${ }^{[4,8]}$ Alfa açısının ölçümü için, femur boynunun ortasından femur başının orta noktasına bir çizgi çizilir. Femur başı orta noktası ile femur başının sferisitesinin bozulduğu anterior femur baş-boyun bileşkesine çizilen çizginin kesişmesi ile oluşan açı, alfa açısı olarak tanımlanmaktadır (Şekil 8). Bu açının patolojik sınır değeri ile ilgili, literatürde yapılmış birkaç çalışma mevcuttur. Güvenli cerrahi dislokasyon ile FAS tedavisi uygulanan bir hasta grubunda, rezeksiyon sonrası sıkışma olmaksızın hareket sağlandığı görülmüş ve bu hastaların cerrahi sonrası grafilerinde yapılan ölçümlerde, alfa açısının $42^{\circ}$ 'nin altında olduğu tespit edilmiştir. Bu açıdan, yazarlar çalışmalarının sonucunda, alfa açısının sınır değeri olarak $42^{\circ}$ 'nin kabul edilmesini önermişlerdir. ${ }^{[14]}$ Buna rağmen, genel popülasyon üzerinde yapılan ve semptomatik hastalar 

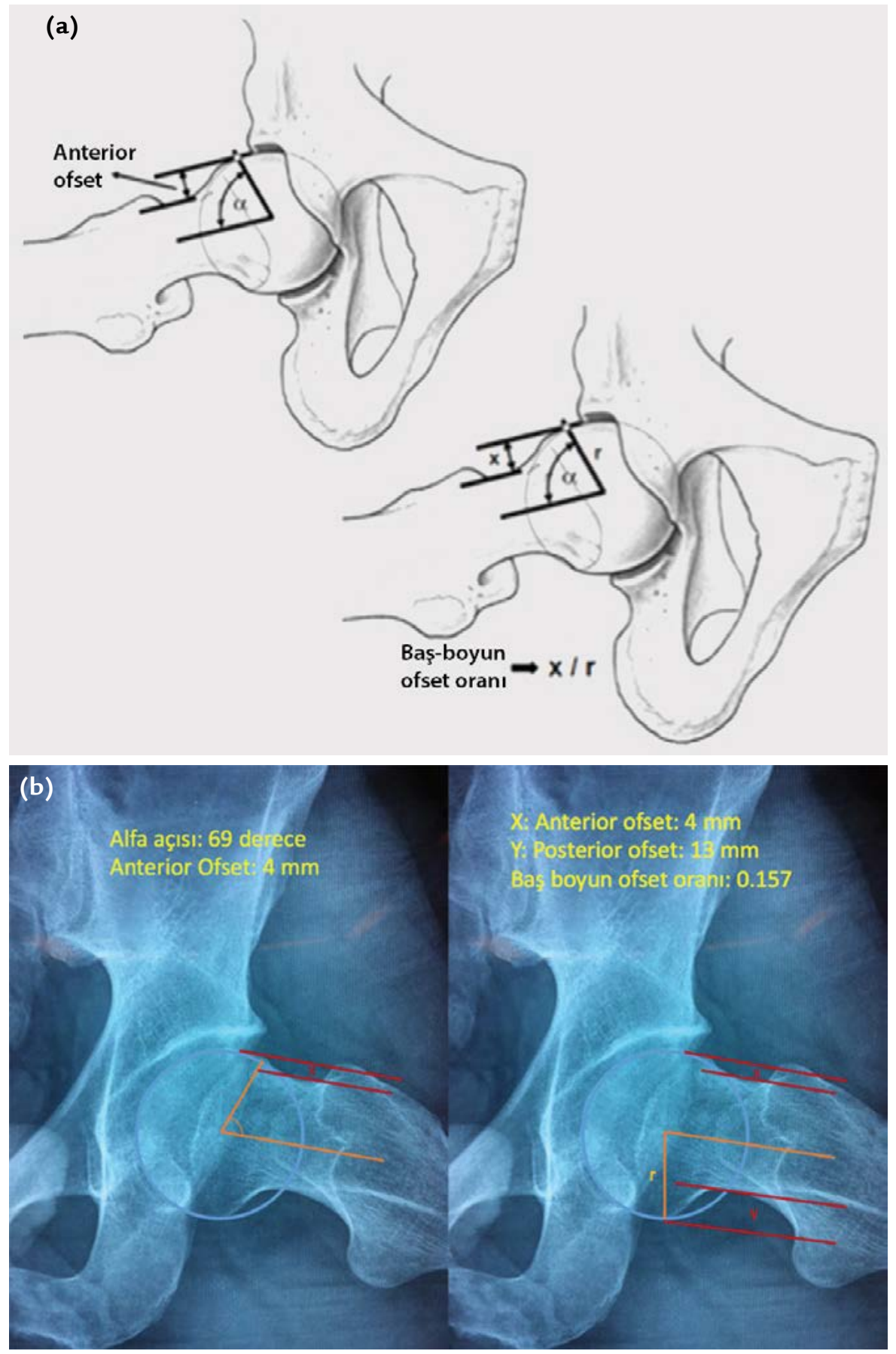

Şekil 8. a, b. Alfa açısı, anterior ofset ve baş-boyun ofset oranının ölçümünün şematik gösterimi (a). Sol kalça cam tipi sıkışması olan hastanın frog-leg grafisinde alfa açısı, anterior ofset ve baş-boyun ofset oranının ölçümü (b).

üzerinde farklı görüntüleme yöntemlerinin kıyaslandığı bazı çalışmalarda, bu açının 50-55'ye kadar normal olarak kabul edilebileceği de bildirilmektedir. ${ }^{[12,13]}$ Bununla birlikte, son dönemde yapılan bir çalışma$\mathrm{da}$, alfa açısındaki düzelmenin klinik sonuçlarla ilişkili olduğu ve cerrahi sonrası alfa açısı $55^{\circ}$ altına indirilen hastalarda, klinik sonuçların daha iyi olduğu bildirilmiştir. ${ }^{[15]}$ Femur başının sferisitesinin değerlendirilmesinde kullanılan diğer bir parametre, anterior femoral ofsettir ve lateral planda femur baş boyun bileşkesi ve 

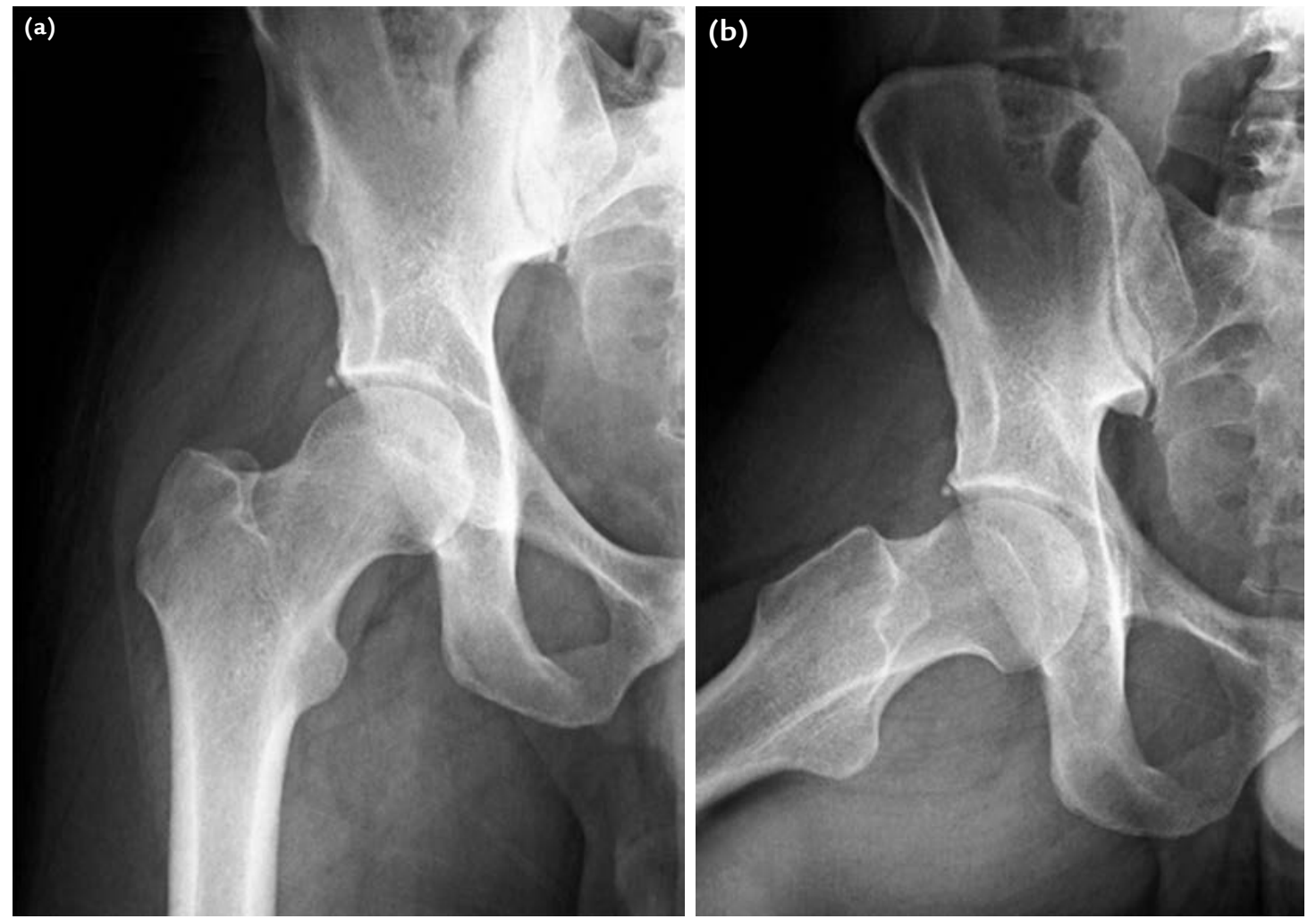

Şekil 9. a, b. Hastanın sağ kalça AP (a) ve frog-leg (b) grafilerinde femoroasetabular sıkışmanın sekonder radyolojik bulgularından biri olan labrum kalsifikasyonu görülmekte.

başın anterioru arasındaki mesafenin ölçümü ile elde edilir. Anterior ofsetin, normalde $10 \mathrm{~mm}$ 'den fazla olması gerekir. FAS'ta bu değer $10 \mathrm{~mm}$ 'nin altındadır. ${ }^{[8]}$ Bu konuda belirlenen bir diğer sayısal parametre, başboyun ofset oranıdır. Lateral grafi üzerinde ölçülen bu parametre için, femur boynunun ve başın orta noktasından geçen bir çizgi çizilir. Sonrasında, bu çizgiye paralel olarak, femur boynu anteriorundan ve femur başı anteriorundan iki çizgi daha çizilir. Bu çizgiler arasındaki mesafenin femur başı yarıçapına bölünmesiyle, baş-boyun ofset oranı elde edilir. Bu oranın 0,17'nin altında olması, cam tipi FAS belirtisidir. ${ }^{[4]}$

Femur proksimalindeki deformitenin sayısal verilerle değerlendirilmesi için tarif edilen diğer bir açısal ölçüm ise, triangüler indekstir. AP planda yapılan ölçümde, femur başının merkezi ile superolaterali arasındaki yarıçap mesafenin, femur başı merkezi ve inferolaterali arasındaki yarıçap mesafesinden $2 \mathrm{~mm}$ fazla olması patolojik olarak değerlendirilir. ${ }^{[4]}$

FAS için, konvansiyonel radyografiler üzerine tanımlanmış sekonder sıkışma bulguları mevcuttur ve çekilen radyografiler bu açıdan incelenmelidir. Bunlardan biri, labrum kalsifikasyonudur ve pincer tipi sıkışmada daha sık görülmektedir (Şekil 9). Labrumun, FAS'ın oluşturduğu dejenerasyon ve yırtıkları zemininde kalsifiye hale gelmesi ile oluşur. Diğer bir sekonder bulgu ise, cam tipi sıkışmalarda görülen, asferik başın asetabulum içine girişi ile asetabulum anterolateralinde oluşan stres kırıklarıdır. Bu bulgu, asetabular kenarda radyodens bir lezyon olarak veya os asetabuli olarak görülebilir. Diğer bir sekonder bulgu ise, femur boynunun anterosuperior kısmında asetabulumla kronik temasına bağlı oluşan, ortası kistik lezyondur. Bu lezyon, herniyasyon cebi (herniation pit) olarak adlandırılır (Şekil 10). ${ }^{[4]}$

\section{SONUÇ}

FAS tanısında, klinik muayenenin yanında konvansiyonel radyoloji temel yardımcı tanı yöntemidir. Hastaların radyolojik incelenmesi için, ideal olarak çekilmiş grafiler üzerinde yapılacak olan değerlendirmeler, tanıya yardımcı olması dışında morfolojik bozukluğun rakamsal olarak da ifade edilmesini sağlayacaktır. Bununla birlikte, tanı ve yapılacak tedavinin planlaması açısından, manyetik rezonans görüntüleme ve bilgisayarlı tomografi incelemeleri de yararlı olacaktır. 

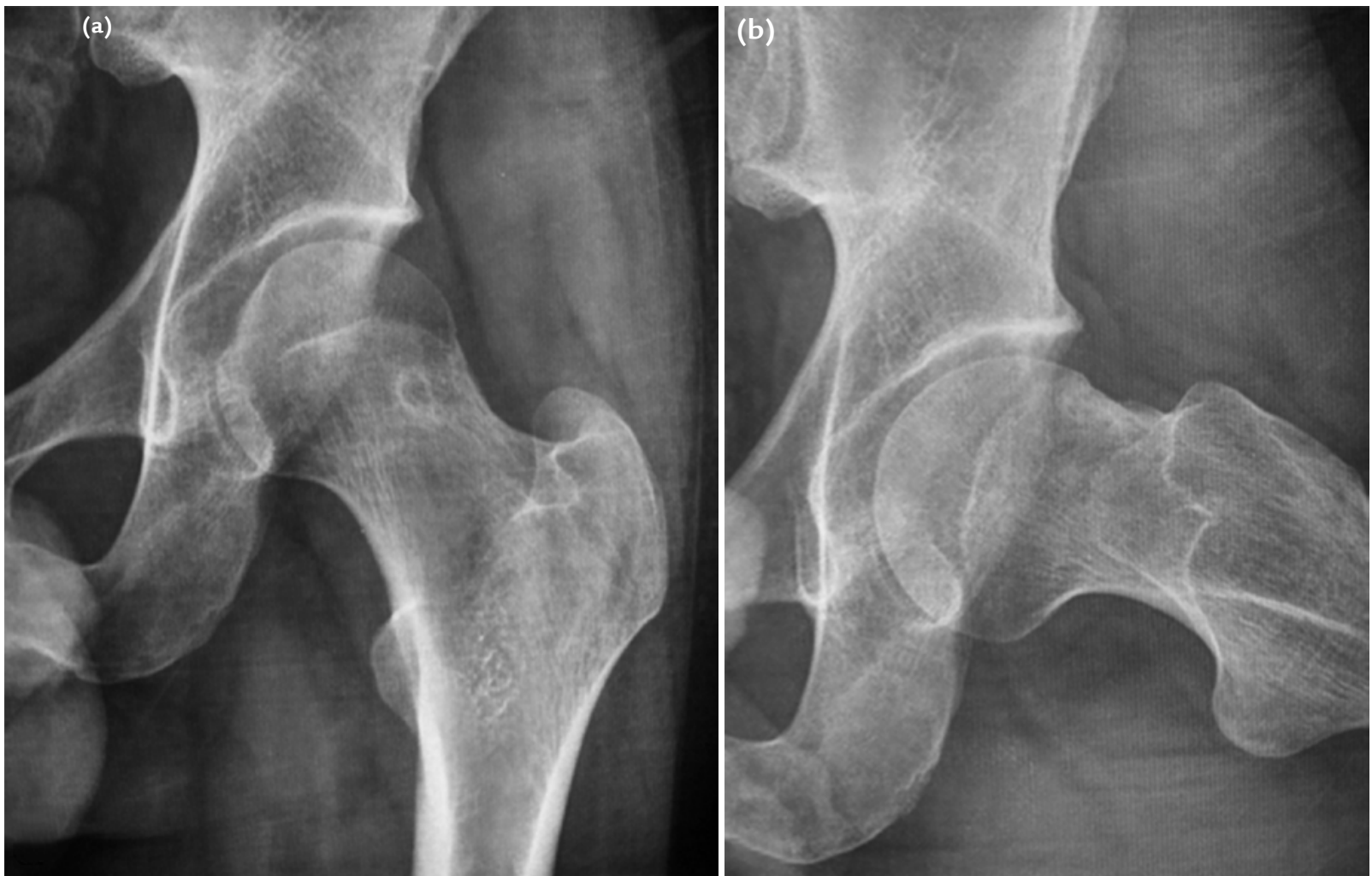

Şekil 10. a, b. Cam tipi sıkışması olan hastanın AP (a) ve lateral (b) grafilerinde femur boynundaki herniyasyon cebinin radyolojik görünümü.

\section{KAYNAKLAR}

1. Ganz R, Parvizi J, Beck M, Leunig M, Nötzli H, Siebenrock KA. Femoroacetabular impingement: a cause for osteoarthritis of the hip. Clin Orthop Relat Res 2003;(417):112-20.

2. Ganz R, Leunig M, Leunig-Ganz K, Harris WH. The etiology of osteoarthritis of the hip: an integrated mechanical concept. Clin Orthop Relat Res 2008;466(2):264-72. Crossref

3. Amanatullah DF, Antkowiak T, Pillay K, Patel J, Refaat M, Toupadakis CA, Jamali AA. Femoroacetabular impingement: current concepts in diagnosis and treatment. Orthopedics 2015;38(3):185-99. Crossref

4. Tannast M, Siebenrock KA, Anderson SE. Femoroacetabular impingement: radiographic diagnosis -what the radiologist should know. Radiologia 2008;50(4):271-84.

5. Dimmick S, Stevens KJ, Brazier D, Anderson SE. Femoroacetabular impingement. Radiol Clin North Am 2013;51(3):337-52. Crossref

6. Tibor LM, Sekiya JK. differential diagnosis of pain around the hip joint. Arthroscopy 2008;24(12):1407-21. Crossref

7. ClohisyJC, Carlisle JC, Beaulé PE, Kim Y, Trousdale RT, Sierra RJ, Leunig M, Schoenecker PL, Millis MB. A systematic approach to the plain radiographic evaluation of the young adult hip. J Bone Joint Surg Am 2008;90 Suppl 4:47-66. Crossref

8. Ito K, Minka MA 2nd, Leunig M, Werlen S, Ganz R. Femoroacetabular impingement and the cam-effect. A MRIbased quantitative anatomical study of the femoral headneck offset. J Bone Joint Surg Br 2001;83(2):171-6.
9. Werner CM, Copeland CE, Ruckstuhl T, Stromberg J, Turen $\mathrm{CH}$, Kalberer F, Zingg PO. Radiographic markers of acetabular retroversion: correlation of the cross-over sign, ischial spine sign and posterior wall sign. Acta Orthop Belg 2010;76(2):166-73.

10. Wassilew GI, Heller MO, Diederichs G, Janz V, Wenzl M, Perka C. Standardized AP radiographs do not provide reliable diagnostic measures for the assessment of acetabular retroversion. J Orthop Res 2012;30(9):1369-76. Crossref

11. Ranawat AS, Schulz B, Baumbach SF, Meftah M, Ganz $R$, Leunig $M$. Radiographic predictors of hip pain in femoroacetabular impingement. HSS J 2011;7(2):115-9. Crossref

12. Nouh MR, SchweitzerME, RybakL, CohenJ. Femoroacetabular impingement: can the alpha angle be estimated? AJR Am J Roentgenol 2008;190(5):1260-2. Crossref

13. Rakhra KS, Sheikh AM, Allen D, Beaulé PE. Comparison of MRI alpha angle measurement planes in femoroacetabular impingement. Clin Orthop Relat Res 2009;467(3):660-5. Crossref

14. Neumann M, Cui Q, Siebenrock KA, BeckM. Impingement-free hip motion: the 'normal' angle alpha after osteochondroplasty. Clin Orthop Relat Res 2009;467(3):699-703. Crossref

15. de Sa D, Urquhart N, Philippon M, Ye JE, Simunovic N, Ayeni OR. Alpha angle correction in femoroacetabular impingement. Knee Surg Sports Traumatol Arthrosc 2014;22(4):812-Crossref 